\title{
OPTIMAL POLICIES FOR INVENTORY MODEL WITH SHORTAGES, TIME-VARYING HOLDING AND ORDERING COSTS IN TRAPEZOIDAL FUZZY ENVIRONMENT
}

\author{
Pavan Kumar \\ Mathematics Division, School of Advanced Science \& Language \\ VIT Bhopal University, India \\ E-mail: pavankmaths@gmail.com
}

Submission: $12 / 19 / 2019$

Revision: 5/14/2020

Accept: 6/3/2020

\section{ABSTRACT}

This paper proposes the optimal policies for a fuzzy inventory model considering the holding cost and ordering cost as continuous functions of time. Shortages are allowed and partially backlogged. The demand rate is assumed in such to be linearly dependent on time during on-hand inventory, while during the shortage period, it remains constant. The inventory problem is formulated in crisp environment. Considering the demand rate, holding cost and ordering cost as trapezoidal fuzzy numbers, the proposed problem is transformed into fuzzy model. For this fuzzy model, the signed distance method of defuzzification is applied to determine the average total cost (ATC) in fuzzy environment. The objective is to optimize the ATC and the order quantity. One solved example is provided in order to show the applicability of the proposed model. The convexity of the cost function is verified with the help of 3D-graph.

Keywords: Inventory Model; Partial Backlogging; Time Dependent Demand Rate; Signed Distance Method.

\begin{tabular}{|l|l|}
\hline \multicolumn{2}{|l|}{ Glossary } \\
\hline TrFN: Trapezoidal Fuzzy Number & ATC: Average Total Cost \\
EOQ: Economic Order Quantity & pdf: Probability Density Function \\
EPQ: Economic Production Quantity & \\
\hline
\end{tabular}


DOI: $10.14807 /$ ijmp.v12i2.1212

\section{INTRODUCTION}

In inventory problems, the ordering cost is associated with ordering and receiving an order, and normally possesses the components- clerical/labor costs of processing orders, inspection and return of poor quality products, transport costs, handling costs. In practical life situations, all the above cost components depend upon time. Therefore, to consider the time dependant ordering cost will undoubtedly be a very close approximation to real case inventory problems.

In literature, many inventory models with deteriorating items were studied by a large number of researchers (Dave \& Patel, 1981; Abad, 1996; Chung \& Ting, 1993; Goyal \& Giri, 2001; Shah \& Shukla, 2009). The optimal pricing and lot-sizing was proposed assuming the conditions of perishability and partial backordering (Abad, 1996). The concept of a reseller under partial backlogging was presented to determine the optimal price and order-size for the inventory model (Abad, 2001). The deterioration may be represented by a random variable with a known probability distribution function (pdf).

An EOQ model for items with weibull distribution deterioration was presented with shortages and trended demand (Jalan; Giri; Chaudhary, 1996). Inventory models with ramp type demand rate, partial backlogging and Weibull deterioration rate was presented (Skouri \& Konstantaras; Ganas, 2009). The ramp-type demand rate was studied by large number of researchers. An EOQ inventory model for Weibull distributed deteriorating items was proposed under ramp type demand and shortages (Mandal, 2010).

In the real life business problems, the demand rate of any item is always variable. Several inventory models have been established by considering time-dependent demand. The time dependent demand was considered in some inventory models (Dave \& Patel, 1981; Chung \& Ting, 1993; Wu \& Cheng, 2005; Mandal, 2010; Dutta \& Kumar, 2015a). A deteriorating inventory model for ( $\mathrm{T}$, si)-policy was studied for time proportional demand function (Dave; Patel, 1981). By considering a linear trend in demand, a heuristic was studied for replenishment of deteriorating items for an inventory problem (Chung \& Ting, 1993). By introducing the inflation when supplier credit linked to order quantity, an inventory model was proposed for time-dependent demand rate (Tripathi, 2011).

In inventory models, one important factor is shortages. In literature, two types of shortages are considered: partial backlogging and full backing. An EOQ model was proposed for deteriorating items with time varying demand and partial backlogging (CHANG; DYE, 1999). 
INDEPENDENT JOURNAL OF MANAGEMENT \& PRODUCTION (IJM\&P)

http://www.ijmp.jor.br

v. 12, n. 2, March-April 2021

ISSN: 2236-269X

DOI: $10.14807 /$ ijmp.v12i2.1212

By considering the partial backlogging shortages, an inventory model for deteriorating items with exponential declining demand was formulated (Wu \& Cheng, 2005). A comparison between two pricing and lot-sizing models with partial backlogging and deteriorated items was proposed by (Teng, Ouyang \& Chen, 2007). A deteriorating inventory model for time dependent demand and holding cost with partial backlogging was introduced by (Mishra \& Singh, 2011).

The determination of optimal selling price as well as the lot size was presented for a varying rate of deterioration and exponential partial backlogging (Dye, 2007a). Afterwards, the joint pricing and ordering was proposed for a deteriorating inventory with partial backlogging (Dye, 2007b). In several cases, the demand rate depends on the selling price of the items. Assuming the price dependent demand rate, an inventory model was presented for deteriorating items and time varying holding cost (Roy, 2008).

In inventory models, the concept of two-level trade credit was also introduced. An EOQ model with non instantaneous receipt and exponential deteriorating item was introduced under two-level trade credit (Liao, 2008). A deteriorating inventory model for waiting time partial backlogging was introduced by (Shah \& Shukla, 2009). An inventory model was proposed by introducing the generalized type demand, deterioration and backorder rates (Hung, 2011). By introducing the multiple-market demand, an optimal production-inventory model was presented for deteriorating items (He, Wang \& Lai, 2010).

In general, the parameters for holding cost, demand, ordering cost, deterioration rate, production cost and idle time cost are not specifically known. Due to uncertainty, we may assume the representation of some or all the parameters by fuzzy sets. The concept of fuzzy sets was introduced first time by (Zadeh, 1965). Some applications of fuzzy set theory to mathematical programming as well supply chain management were studied by (Zimmermann, 1985), (Wang \& Shu, 2005).

The (Q, r) inventory model with backorder discount in fuzzy demand and fuzzy ordering cost was proposed by (Ho, et al., 2007). The fuzzy setup cost as well as fuzzy ordering cost was introduced for determining the single-vender and single-buyer inventory strategy (Yang, Tu \& Wang, 2007). An interval-type uncertainty was introduced in inventory parameters. An interval number approach was applied to a partial backlogging inventory model for deteriorating items with time-varying demand and holding cost (Dutta \& Kumar, 2015a). 
DOI: 10.14807/ijmp.v12i2.1212

The global criteria method was suggested to solve the inventory model with variable holding cost and partial backlogging under interval uncertainty (Kumar \& Keerthika, 2018). Uncertainty of neutrosophic type was also proposed. The optimal value of neutrosophic complex programming problem was determined by using lexicographic order (Khalifa, Kumar \& Smarandache, 2020).

The concepts of parabolic holding cost with salvage value were also introduced. An inventory planning problem was presented for time-varying linear demand and parabolic holding cost with salvage value (Kumar, 2019). Some applications of optimizations techniques were also suggested to various fields. In the field of a micro-company of the graphic sector, an application of a mathematical model for cost minimization was studied (Rodrigues, Marins \& Souza, 2017).

In the field of inventory, an application of fuzzy goal programming approach was implemented to multi- objective linear fractional inventory model (Dutta \& Kumar, 2015b). In joint inventory-production problems, the production depends on demand. Moreover, the demand depends on the number of population of customers, selling price as well as advertisement. A fuzzy EPQ model for non-instantaneous deteriorating items was presented, where the production rate depends on demand which is proportional to population, selling price as well as advertisement (Biswas \& Islam, 2019).

\subsection{Motivation:}

Several researchers studied the inventory problem with constant deterioration, timesensitive demand and holding cost (Tripathi, 2011; Dutta \& Kumar, 2015a; Kumar \& Keerthika, 2018), etc. For instance, Dutta and Kumar (2015a) formulated such a model, and applied the interval number method to solve it. Kumar and Keerthika (2018) also studied a similar model using uncertainty in model variables and parameters. They did not consider the trapezoidal fuzzy number to deal the uncertainties. Also, the ordering cost may be considered as time dependent along with the time-sensitive holding cost.

In present research paper, we propose a fuzzy inventory model with shortages. We consider the holding and ordering costs as continuous functions of time. Our objective is to determine the optimal control policies for the proposed model.

\subsection{Main Contribution:}

The main contributions of the present paper are summarized below: 
DOI: 10.14807/ijmp.v12i2.1212

- Introducing the time-sensitive holding cost as well as ordering cost.

- Applying the solution method based on defuzzification of trapezoidal fuzzy numbers.

- Convexity is justified with the help of a 3D-graph..

- Based on the results, some managerial implications are proposed.

The remaining outlay of the paper is organized as follows. In section 2, we describe some definitions. In section 3, the problem description and formulation is provided. In section 4, a fuzzy mathematical model of the proposed problem is developed. In section 5, the solution procedure is described. In section 6, a solved example is given to explain the procedure. In section 7, some special cases are discussed. In section 8, managerial implications and limitations are explored. In the last, the conclusions and future directions are reported in section 9.

\section{SOME DEFINITIONS}

- Definition 1: (Dutta \& Kumar, 2015b)

A Trapezoidal Fuzzy Number $(\operatorname{TrFN})$, denoted by $\tilde{A}=\left(a_{1}, a_{2}, a_{3}, a_{4}\right)$ is defined by the membership function $\mu_{\tilde{A}}$ as:

$$
\mu_{\tilde{A}}(x)=\left\{\begin{array}{lr}
\mathrm{L}(\mathrm{x})=\frac{x-a_{1}}{a_{2}-a_{1}}, & \text { when } a_{1} \leq \mathrm{x} \leq a_{2} \\
1, & \text { when } a_{2} \leq \mathrm{x} \leq a_{3} \\
\mathrm{R}(\mathrm{x})=\frac{a_{4}-x}{a_{4}-a_{3}}, & \text { when } a_{3} \leq \mathrm{x} \leq a_{4} \\
0, & \text { otherwise. }
\end{array}\right.
$$

- Definition 2: (Dutta \& Kumar, 2015b)

A fuzzy set is called in LR-Form, if there exist reference functions L (for left), R (for right), and scalars $m>0$ and $n>0$ with membership function

$$
\mu_{\tilde{A}}(x)=\left\{\begin{array}{cc}
\mathrm{L}\left(\frac{\sigma-x}{\mathrm{~m}}\right), & \text { for } \mathrm{x} \leq \sigma \\
1, & \text { for } \sigma \leq \mathrm{x} \leq \gamma \\
\mathrm{R}\left(\frac{\mathrm{x}-\gamma}{\mathrm{n}}\right), & \text { for } \mathrm{x} \geq \gamma
\end{array}\right.
$$

Where $\sigma$ is a real number called the mean value of $\hat{A}, \mathrm{~m}$ and $\mathrm{n}$ are called the left and right spreads, respectively. The functions $L$ and $R$ map $R^{+} \rightarrow[0,1]$, and are decreasing. A $L R$-Type fuzzy number can be represented as $\tilde{A}=(\sigma, \gamma, m, n)_{L R}$. 
DOI: $10.14807 /$ ijmp.v12i2.1212

- Definition 3: (Dutta \& Kumar, 2015b)

The fuzzy arithmetic operations under the functional principle for trapezoidal fuzzy numbers are described below. Let $\tilde{A}=\left(a_{1}, a_{2}, a_{3}, a_{4}\right)$ and $\tilde{B}=\left(b_{1}, b_{2}, b_{3}, b_{4}\right)$ be two trapezoidal fuzzy numbers, and let $k$ be any scalar. Then arithmetical operations are defined as:

(i) Fuzzy Addition: $\tilde{A} \oplus \tilde{B}=\left(a_{1}+b_{1}, a_{2}+b_{2}, a_{3}+b_{3}, a_{4}+b_{4}\right)$.

(ii) Fuzzy Multiplication: $\tilde{A} \otimes \tilde{B}=\left(a_{1} b_{1}, a_{2} b_{2}, a_{3} b_{3}, a_{4} b_{4}\right)$.

(iii) Fuzzy Subtraction: $\tilde{A} \ominus \tilde{B}=\left(a_{1}-b_{4}, a_{2}-b_{3}, a_{3}-b_{2}, a_{4}-b_{1}\right)$

(iv) Fuzzy Division: $\tilde{A} \varnothing \tilde{B}=\left(\frac{a_{1}}{b_{4}}, \frac{a_{2}}{b_{3}}, \frac{a_{3}}{b_{2}}, \frac{a_{4}}{b_{1}}\right)$

(v) Fuzzy Scalar Multiplication: $\mathrm{k} \otimes \tilde{A}= \begin{cases}\left(k a_{1}, k a_{2}, k a_{3}, k a_{4}\right), & k \geq 0 \\ \left(k a_{4}, k a_{3}, k a_{2}, k a_{1}\right), & k<0\end{cases}$

- Definition 4: (Dutta \& Kumar, 2015b)

Let $\tilde{A}$ be a fuzzy set defined on R. Then the Signed Distance of $\tilde{A}$ is defined as:

$$
d(\tilde{A}, 0)=\frac{1}{2} \int_{0}^{1}\left[A_{L}(\alpha)+A_{R}(\alpha)\right] \mathrm{d} \alpha
$$

where $A_{\alpha}=\left[A_{L}(\alpha), A_{R}(\alpha)\right]=[a+(b-a) \alpha, d-(d-c) \alpha], \alpha \in[0,1]$, is $\alpha-$ cut of fuzzy set $\tilde{A}$, which is a close interval.

\section{PROBLEM DESCRIPTION AND FORMULATION}

The main objective of this paper is to minimize the total cost of the proposed inventory model, that possesses the following features: (i) the demand rate is a time dependent function, (ii) the holding cost is an increasing linear function of the storage time, and (iii) the ordering cost depends on the total time elapsed up to the beginning of each cycle.

\subsection{Notations}

The following notations are used in this paper.

$c_{1}(\mathrm{t}) \quad$ : Holding cost per unit per time unit (Time dependant).

$c_{2} \quad:$ Purchase cost per unit

$c_{3} \quad$ : Shortage cost per unit per time unit 
DOI: $10.14807 /$ ijmp.v12i2.1212

$$
\begin{aligned}
& c_{4} \quad: \text { Cost of lost sales per unit } \\
& \theta \quad \text { : Deterioration rate } \\
& T \quad \text { : Cycle time (decision variable) } \\
& t_{1} \quad \text { : Time at which shortage starts, i.e., inventory exhausted time, (decision } \\
& \text { variable), } 0 \leq t_{1} \leq T \\
& T-t_{1} \text { : Length of waiting time } \\
& I_{\max } \quad \text { : Maximum inventory level during a cycle of length } T \\
& D_{B} \quad \text { : Maximum amount of demand backlogged during a cycle of length } T \\
& Q \quad:\left(=I_{\max }+D_{B}\right) \text { order quantity during a cycle of length } T \\
& C_{o}(t) \quad \text { : Time dependant ordering cost per order. } \\
& C_{H} \quad \text { : Inventory holding cost per cycle } \\
& C_{D} \quad \text { : Deterioration cost per cycle } \\
& C_{S} \quad \text { : Shortage cost per cycle } \\
& C_{L} \quad \text { : Lost sales cost per cycle } \\
& C\left(t_{1}, T\right) \text { : Average total cost per time unit per cycle } \\
& X^{*} \quad \text { : Optimal value of } \mathrm{X} \text {, where } \mathrm{X} \text { is any variable or parameter. } \\
& I(t) \quad: \text { Inventory level at time, } 0 \leq t \leq T \\
& I_{1}(t) \quad \text { : Inventory level during the period }\left[0, t_{1}\right] \\
& I_{2}(t) \quad \text { : Inventory level during the period }\left[t_{1}, T\right]
\end{aligned}
$$

\subsection{Assumptions}

The proposed model is based on the following assumptions:

I. Inventory system involves only one item.

II. Planning horizon is infinite. Each replenishment cycle is of same length, $T$. Only one order is placed for the period $[0, T]$. No lead time between placing an order and arrival of the order.

III. Deteriorating rate, $\theta(0<\theta<1)$, is constant and occurs as soon as items are received into inventory. There is no replacement or repair of deteriorated units. 
DOI: 10.14807/ijmp.v12i2.1212

IV. Demand during the on-hand inventory, the demand rate, $R(t)$ increases linearly with respect to time, and during the shortages period, the demand rate becomes constant:

$$
R(t)=\left\{\begin{array}{l}
a t, \text { when } \mathrm{I}(\mathrm{t})>0 \\
b, \text { when } \mathrm{I}(\mathrm{t}) \leq 0,
\end{array}, \text { where } a, b>0\right. \text { are arbitrary constants. }
$$

V. Shortages are allowed and partially backlogged with backordered rate

$$
B(t)=\frac{1}{1+\delta(\mathrm{T}-\mathrm{t})},
$$

The backlogging parameter $\delta>0$, and $\mathrm{t}_{1} \leq \mathrm{t} \leq \mathrm{T}$. For the special case with $\delta=0, B(t)$ $=1$, that is, the fully

backlogged case. In the proposed model, we assume $\delta<1$ to approximate by Maclaurin's series.

VI. Holding cost, $c_{1}(t)$ per unit per time unit is time dependant and assume its function form is

$$
c_{1}(t)=h t \text {, where } h>0 \text { is the holding cost scale parameter. }
$$

VII. The ordering cost, $C_{o}(t)$ depends on the total time elapsed up to the beginning of each cycle and is taken as

$$
C_{o}(t)=k_{1} t_{1}+k_{2}
$$

where $0 \leq t_{1} \leq T, k_{1} \geq 0$, and $k_{2}>0$ is the ordering cost at time zero.

\subsection{MATHEMATICAL MODEL}

The inventory is replenished at time $t=0$, when the inventory level is at its maximum, $I_{\max }$. Afterwards, the inventory level begins to decrease during the period $\left[0, t_{1}\right]$, and eventually becomes zero, when $t=t_{1}$. Further, during the period $\left[t_{1}, T\right]$, there is partially backlogging. The governing differential equations are:

$$
\begin{array}{ll}
\frac{d I_{1}(t)}{d t}+\theta \cdot I_{1}(t)=-a t, & 0 \leq t \leq t_{1} \\
\frac{d I_{2}(t)}{d t}=\frac{-b}{1+\delta(\mathrm{T}-\mathrm{t})}, & t_{1} \leq t \leq T
\end{array}
$$

$$
\text { With boundary conditions: } \left.\begin{array}{l}
I_{1}(t)=I_{2}(t)=0 \text { at } t=t_{1} \\
I_{1}(t)=I_{\max } \text { at } t=0
\end{array}\right\}
$$

For $I(t)>0$, the inventory level decreases due to the demand as well as deterioration, and the inventory level is governed by (1). Using the boundary conditions, the solution of (1) is given by 
DOI: 10.14807/ijmp.v12i2.1212

$$
I_{1}(t)=-\frac{a}{\theta}\left[\left(\mathrm{t}-\frac{1}{\theta}\right)-\left(t_{1}-\frac{1}{\theta}\right) e^{\theta\left(t_{1}-t\right)}\right], 0 \leq t \leq t_{1}
$$

Therefore, the maximum level of the proposed inventory model, for each cycle, can be written as follows:

$$
I_{\max }=I_{1}(0)=\frac{a}{\theta}\left[\frac{1}{\theta}+\left(t_{1}-\frac{1}{\theta}\right) e^{\theta t_{1}}\right]
$$

For $I(t) \leq 0$, the inventory level is sensitive with the demand. When the demand is more, the inventory level starts to decreases, and vice-versa. However, we assume that a fraction of demand is backlogged. The level of the inventory is governed by (2). Applying the boundary conditions, the solution of (2) can be written as:

$$
I_{2}(t)=\frac{b}{\delta}\left[\log \{1+\delta(\mathrm{T}-\mathrm{t})\}-\log \left\{1+\delta\left(\mathrm{T}-t_{1}\right)\right\}\right], t_{1} \leq t \leq T
$$

As per the calculations illustrated in Appendix-A, we can write the order quantity as follows:

$$
Q=a\left(\frac{t_{1}^{2}}{2}\right)+\mathrm{b}\left[\mathrm{T}-t_{1}-\frac{\delta\left(\mathrm{T}-t_{1}\right)^{2}}{2}\right]
$$

Hence, the average total cost per unit time per cycle is

$$
\Rightarrow C\left(t_{1}, T\right)=\frac{1}{\mathrm{~T}}\left\{k_{1} t_{1}+k_{2}+\frac{a h}{6 \theta} t_{1}^{3}+\frac{c_{2} a}{2} \theta t_{1}^{3}+\mathrm{b}\left(\frac{\mathrm{c}_{3}+\delta \mathrm{c}_{4}}{\delta}\right)\left[\mathrm{T}-\mathrm{t}_{1}-\frac{\log \left[1+\delta\left(\mathrm{T}-\mathrm{t}_{1}\right)\right]}{\delta}\right]\right\}
$$

Applying the Macraurin series, and ignoring higher power terms, we get

$$
\Rightarrow C\left(t_{1}, T\right)=\frac{1}{T}\left\{t_{1}^{3}\left(\frac{a h}{6 \theta}+\frac{c_{2} a \theta}{2}\right)+\frac{b}{2}\left(c_{3}+\delta c_{4}\right)\left(T-t_{1}\right)^{2}+k_{1} t_{1}+k_{2}\right\}
$$

\section{FUZZY MATHEMATICAL MODEL}

In real-life situations, the decision maker has to face the ambiguity in model parameters. In this research paper, to face with the fuzzy type uncertainty and ambiguity in parameters of the inventory model, we consider the demand rate, holding cost and ordering cost as represented by trapezoidal fuzzy numbers $(\mathrm{TrFN})$ as follows:

$$
\begin{gathered}
\tilde{a}=\left(\mathrm{a}_{1}, \mathrm{a}_{2}, \mathrm{a}_{3}, \mathrm{a}_{4}\right) \\
\tilde{b}=\left(\mathrm{b}_{1}, \mathrm{~b}_{2}, \mathrm{~b}_{3}, \mathrm{~b}_{4}\right) \\
\tilde{h}=\left(\mathrm{h}_{1}, \mathrm{~h}_{2}, \mathrm{~h}_{3}, \mathrm{~h}_{4}\right) \\
\tilde{k}_{1}=\left(k_{11}, k_{12}, k_{13}, k_{14}\right) \\
\tilde{k}_{2}=\left(k_{21}, k_{22}, k_{23}, k_{24}\right)
\end{gathered}
$$

Therefore, we can the average total cost function per unit time in fuzzy environment case, as follows: 
ISSN: 2236-269X

DOI: 10.14807/ijmp.v12i2.1212

$$
\begin{aligned}
\tilde{C}\left(t_{1}, T\right)= & \frac{1}{T}\left\{t_{1}^{3}\left(\frac{\tilde{a} \tilde{h}}{6 \theta}+\frac{c_{2} \tilde{a} \theta}{2}\right)+\frac{\tilde{b}}{2}\left(c_{3}+\delta c_{4}\right)\left(T-t_{1}\right)^{2}+\tilde{k}_{1} t_{1}+\tilde{k}_{2}\right\} \\
= & \frac{1}{T}\left\{t_{1}^{3}\left[\frac{1}{6 \theta}\left(a_{1}, a_{2}, a_{3}, a_{4}\right)\left(h_{1}, h_{2}, h_{3}, h_{4}\right)+\frac{c_{2} \theta}{2}\left(a_{1}, a_{2}, a_{3}, a_{4}\right)\right]\right. \\
& +\frac{\left(c_{3}+\delta c_{4}\right)\left(T-t_{1}\right)^{2}}{2}\left(b_{1}, b_{2}, b_{3}, b_{4}\right) \\
& \left.+\left(k_{11}, k_{12}, k_{13}, k_{14}\right) t_{1}+\left(k_{21}, k_{22}, k_{23}, k_{24}\right)\right\} \\
= & \frac{1}{T}\left\{t_{1}^{3}\left(\frac{a_{1} h_{1}}{6 \theta}+\frac{c_{2} \theta}{2} a_{1} \frac{a_{2} h_{2}}{6 \theta}+\frac{c_{2} \theta}{2} a_{2}, \frac{a_{3} h_{3}}{6 \theta}+\frac{c_{2} \theta}{2} a_{3}, \frac{a_{4} h_{4}}{6 \theta}+\frac{c_{2} \theta}{2} a_{4}\right)\right.
\end{aligned}
$$

$\frac{\left(c_{3}+\delta c_{4}\right)\left(T-t_{1}\right)^{2}}{2}\left(b_{1}, b_{2}, b_{3}, b_{4}\right)$

$$
+\left(k_{11} t_{1}+k_{21}, k_{12} t_{1}+k_{22}, k_{13} t_{1}+k_{23}, k_{14} t_{1}+k_{24}\right)
$$

$=(W, X, Y, Z),($ say $)$,

where

$$
\begin{aligned}
& W=\frac{1}{T}\left\{a_{1} t_{1}^{3}\left(\frac{h_{1}}{6 \theta}+\frac{c_{2} \theta}{2}\right)+\frac{b_{1}\left(c_{3}+\delta c_{4}\right)\left(T-t_{1}\right)^{2}}{2}+k_{11} t_{1}+k_{21}\right\} \\
& X=\frac{1}{T}\left\{a_{2} t_{1}^{3}\left(\frac{h_{2}}{6 \theta}+\frac{c_{2} \theta}{2}\right)+\frac{b_{2}\left(c_{3}+\delta c_{4}\right)\left(T-t_{1}\right)^{2}}{2}+k_{12} t_{1}+k_{22}\right\} \\
& Y=\frac{1}{T}\left\{a_{3} t_{1}^{3}\left(\frac{h_{3}}{6 \theta}+\frac{c_{2} \theta}{2}\right)+\frac{b_{3}\left(c_{3}+\delta c_{4}\right)\left(T-t_{1}\right)^{2}}{2}+k_{13} t_{1}+k_{23}\right\} \\
& Z=\frac{1}{T}\left\{a_{4} t_{1}^{3}\left(\frac{h_{4}}{6 \theta}+\frac{c_{2} \theta}{2}\right)+\frac{b_{4}\left(c_{3}+\delta c_{4}\right)\left(T-t_{1}\right)^{2}}{2}+k_{14} t_{1}+k_{24}\right\}
\end{aligned}
$$

The $\alpha$ - cuts, $C_{L}(\alpha)$ and $C_{R}(\alpha)$, of trapezoidal fuzzy number $\tilde{C}\left(t_{1}, T\right)$, can be written as follows:

$$
\begin{aligned}
& C_{L}(\alpha)=W+(X-W) \alpha \\
& =\frac{1}{T}\left\{a_{1} t_{1}^{3}\left(\frac{h_{1}}{6 \theta}+\frac{c_{2} \theta}{2}\right)+\frac{b_{1}\left(c_{3}+\delta c_{4}\right)\left(T-t_{1}\right)^{2}}{2}+k_{11} t_{1}+k_{21}\right\}+\frac{\alpha}{T}\left\{\frac{t_{1}^{3}}{6 \theta}\left(a_{2} h_{2}-a_{1} h_{1}\right)+\frac{c_{2} \theta t_{1}^{3}}{2}\left(a_{2}-\right.\right. \\
& \left.\left.a_{1}\right)+\frac{\left(c_{3}+\delta c_{4}\right)\left(T-t_{1}\right)^{2}\left(b_{2}-b_{1}\right)}{2}+t_{1}\left(k_{12}-k_{11}\right)+k_{22}-k_{21}\right\} \\
& \quad \text { And } C_{R}(\alpha)=Z-(Z-Y) \alpha \\
& =\frac{1}{T}\left\{a_{4} t_{1}^{3}\left(\frac{h_{4}}{6 \theta}+\frac{c_{2} \theta}{2}\right)+\frac{b_{4}\left(c_{3}+\delta c_{4}\right)\left(T-t_{1}\right)^{2}}{2}+k_{14} t_{1}+k_{24}\right\}+\frac{\alpha}{T}\left\{\frac{t_{1}^{3}}{6 \theta}\left(a_{4} h_{4}-a_{3} h_{3}\right)+\frac{c_{2} \theta t_{1}^{3}}{2}\left(a_{4}-\right.\right. \\
& \left.\left.a_{3}\right)+\frac{\left(c_{3}+\delta c_{4}\right)\left(T-t_{1}\right)^{2}\left(b_{4}-b_{3}\right)}{2}+t_{1}\left(k_{14}-k_{13}\right)+k_{24}-k_{23}\right\}
\end{aligned}
$$


DOI: $10.14807 /$ ijmp.v12i2.1212

$\Rightarrow \int_{0}^{1}\left[C_{L}(\alpha) d \alpha=\frac{1}{T}\left\{a_{1} t_{1}^{3}\left(\frac{h_{1}}{6 \theta}+\frac{c_{2} \theta}{2}\right)+\frac{b_{1}\left(c_{3}+\delta c_{4}\right)\left(T-t_{1}\right)^{2}}{2}+k_{11} t_{1}+k_{21}\right\}+\frac{1}{2 T}\left\{\frac{t_{1}^{3}}{6 \theta}\left(a_{2} h_{2}-\right.\right.\right.$

$\left.\left.a_{1} h_{1}\right)+\frac{c_{2} \theta t_{1}^{3}}{2}\left(a_{2}-a_{1}\right)+\frac{\left(c_{3}+\delta c_{4}\right)\left(T-t_{1}\right)^{2}\left(b_{2}-b_{1}\right)}{2}+t_{1}\left(k_{12}-k_{11}\right)+k_{22}-k_{21}\right\}$

And $\int_{0}^{1} C_{R}(\alpha) d \alpha=\frac{1}{T}\left\{a_{4} t_{1}^{3}\left(\frac{h_{4}}{6 \theta}+\frac{c_{2} \theta}{2}\right)+\frac{b_{4}\left(c_{3}+\delta c_{4}\right)\left(T-t_{1}\right)^{2}}{2}+k_{14} t_{1}+k_{24}\right\}+\frac{1}{2 T}\left\{\frac{t_{1}^{3}}{6 \theta}\left(a_{4} h_{4}-\right.\right.$ $\left.\left.a_{3} h_{3}\right)+\frac{c_{2} \theta t_{1}^{3}}{2}\left(a_{4}-a_{3}\right)+\frac{\left(c_{3}+\delta c_{4}\right)\left(T-t_{1}\right)^{2}\left(b_{4}-b_{3}\right)}{2}+t_{1}\left(k_{14}-k_{13}\right)+k_{24}-k_{23}\right\}$

By applying the Signed Distance Method, the defuzzified value of average total cost, which is represented by the fuzzy number $\tilde{C}\left(t_{1}, T\right)$, can be written as follows:

$$
\begin{aligned}
& C_{d S}\left(t_{1}, \mathrm{~T}\right)=\frac{1}{2} \int_{0}^{1}\left[C_{L}(\alpha)+C_{R}(\alpha)\right] d \alpha, \\
& \frac{1}{2}\left[\begin{array}{c}
\frac{1}{T}\left\{a_{1} t_{1}^{3}\left(\frac{h_{1}}{6 \theta}+\frac{c_{2} \theta}{2}\right)+\frac{b_{1}\left(c_{3}+\delta c_{4}\right)\left(T-t_{1}\right)^{2}}{2}+k_{11} t_{1}+k_{21}\right\} \\
+\frac{1}{2 T}\left\{\frac{t_{1}^{3}}{6 \theta}\left(a_{2} h_{2}-a_{1} h_{1}\right)+\frac{c_{2} \theta t_{1}^{3}}{2}\left(a_{2}-a_{1}\right)+\frac{\left(c_{3}+\delta c_{4}\right)\left(T-t_{1}\right)^{2}\left(b_{2}-b_{1}\right)}{2}+t_{1}\left(k_{12}-k_{11}\right)+k_{22}-k_{21}\right\} \\
+\frac{1}{T}\left\{a_{4} t_{1}^{3}\left(\frac{h_{4}}{6 \theta}+\frac{c_{2} \theta}{2}\right)+\frac{b_{4}\left(c_{3}+\delta c_{4}\right)\left(T-t_{1}\right)^{2}}{2}+k_{14} t_{1}+k_{24}\right\} \\
+\frac{1}{2 T}\left\{\frac{t_{1}^{3}}{6 \theta}\left(a_{4} h_{4}-a_{3} h_{3}\right)+\frac{c_{2} \theta t_{1}^{3}}{2}\left(a_{4}-a_{3}\right)+\frac{\left(c_{3}+\delta c_{4}\right)\left(T-t_{1}\right)^{2}\left(b_{4}-b_{3}\right)}{2}+t_{1}\left(k_{14}-k_{13}\right)+k_{24}-k_{23}\right\}
\end{array}\right] \\
& =
\end{aligned}
$$

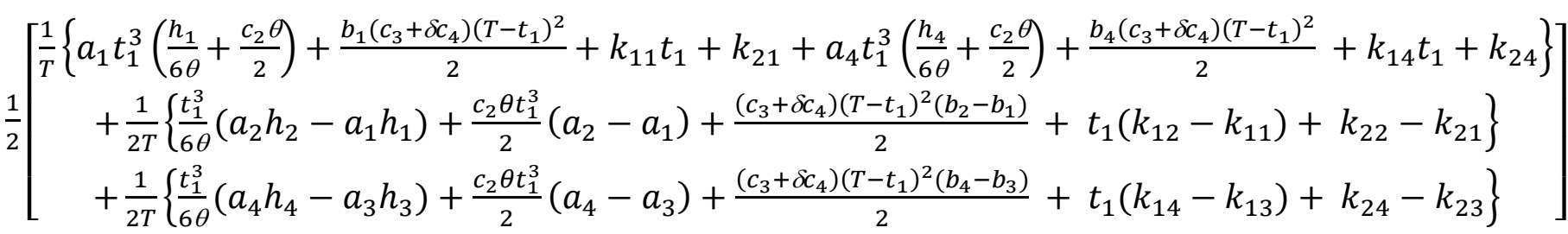

Hence, the optimization problem can be written as:

Minimize $C_{d s}\left(t_{1}, \mathrm{~T}\right)$

Subject to $t_{1}<T$

and $t_{1} \geq 0, T \geq 0$

\section{SOLUTION PROCEDURE}

In this section, the solution procedure for the fuzzy model is presented. Since the objective is to minimize the total cost $C_{d s}\left(t_{1}, \mathrm{~T}\right)$ with respect to the decision variables $t_{1}$ and $\mathrm{T}$; the necessary conditions for minimizing the total cost are:

$$
\frac{\partial C_{d S}\left(t_{1}, \mathrm{~T}\right)}{\partial t_{1}}=0, \text { and } \frac{\partial C_{d S}\left(t_{1}, \mathrm{~T}\right)}{\partial T}=0
$$


DOI: $10.14807 /$ ijmp.v12i2.1212

The sufficient conditions for maximizing the cost function $C_{d s}\left(t_{1}, \mathrm{~T}\right)$ are:

$\left[\frac{\partial^{2} C_{d S}\left(t_{1}, T\right)}{\partial^{2} t_{1}}\right]_{\left(t_{1}^{*}, T^{*}\right)}>0, \quad\left[\frac{\partial^{2} C_{d S}\left(t_{1}, T\right)}{\partial^{2} T}\right]_{\left(t_{1}^{*}, T^{*}\right)}>0$, and $\quad\left[\left[\frac{\partial^{2} C_{d S}\left(t_{1}, T\right)}{\partial^{2} t_{1}}\right]\left[\frac{\partial^{2} C_{d S}\left(t_{1}, T\right)}{\partial^{2} T}\right]-\right.$ $\left[\left[\frac{\partial^{2} C_{d S}\left(t_{1}, T\right)}{\partial t_{1} \partial T}\right]^{2}\right]_{\left(t_{1}^{*}, T^{*}\right)}>0$

The satisfaction of these conditions confirms the convexity of the cost function $C_{d S}\left(t_{1}, T\right)$.

\section{SOLVED EXAMPLE}

Consider an inventory situation with crisp parameters having the following values:

$$
R(t)=\left\{\begin{array}{c}
120 t, \text { when } \mathrm{I}(\mathrm{t})>0 \\
100, \text { when } \mathrm{I}(\mathrm{t}) \leq 0,
\end{array},\right.
$$

where $a=120$, and $b=100$, Ordering cost parameter $k_{1}=4$, and $k_{2}=80, \mathrm{c}_{1}(\mathrm{t})$ $=h t=0.33 t, \theta=0.07, \delta=0.5, c_{2}=2.5, c_{3}=10, c_{4}=5$.

6.1. Crisp Model. The optimal solutions are as follows:

$$
t_{1}^{*}=1.5228, \quad T^{*}=1.5871, \quad C^{*}{ }_{d S}\left(t_{1}, \mathrm{~T}\right)=80.2626 .
$$

6.2. Fuzzy Model. We set some trapezoidal fuzzy numbers as follows:

$$
\begin{gathered}
\tilde{a}=(100,110,130,140) \\
\tilde{b}=(80,90,110,120) \\
\tilde{h}=(0.15,0.25,0.50,0.60) \\
\tilde{k}_{1}=(2,3,5,6) \\
\tilde{k}_{2}=(60,70,90,100)
\end{gathered}
$$

For each of these input parameters, the variations in the values are arranged arbitrary and their defuzzified values are computed by applying the signed distance method. Applying the proposed solution procedure on package- MATHEMATICA-8.0, the optimal solutions are as follows:

$$
t_{1}^{*}=1.132, T^{*}=1.550, \quad C^{*}{ }_{d S}\left(t_{1}, \mathrm{~T}\right)=102.0,
$$

\subsection{Convexity.}

The convexity of the cost function $C^{*} d S$ is shown graphically in Figure 1 and Figure 2. 
DOI: 10.14807/ijmp.v12i2.1212

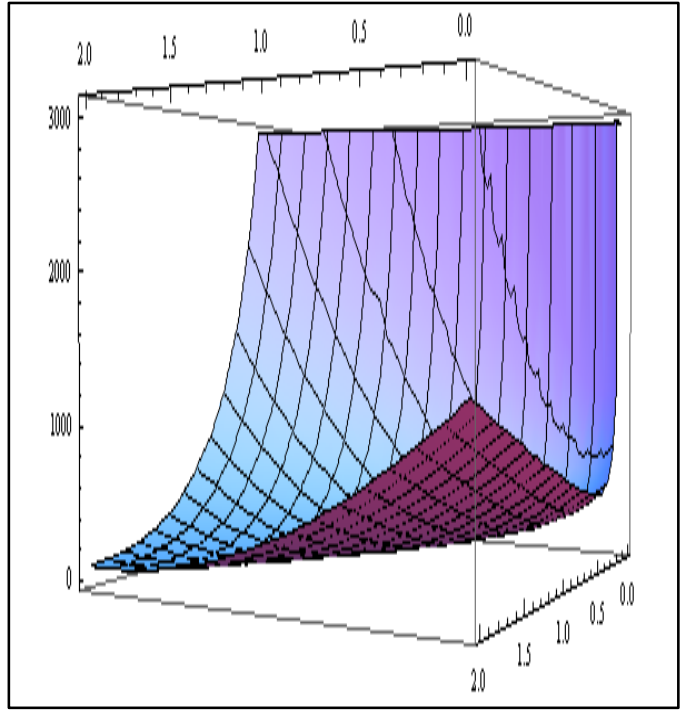

Figure 1: Convexity in Crisp Model

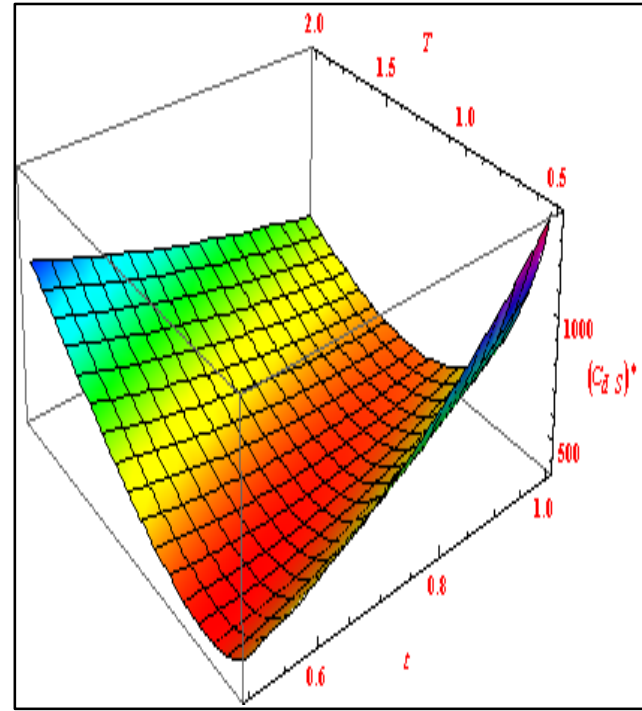

Figure 2: Convexity in Fuzzy Model

The obtained results are summarized in Table- 1 . The comparison for both models between the Time parameters is illustrated in Figure 3, while the comparison between the cost function values is illustrated in Figure 4.

Table 1: Optimal Results

\begin{tabular}{|c|c|c|c|}
\hline & $t_{1}{ }^{*}$ & $T^{*}$ & $C^{*}{ }_{d S}\left(t_{1}, \mathrm{~T}\right)$ \\
\hline Crisp Model & 1.5228 & 1.5871 & 80.2626 \\
\hline Fuzzy Model & 1.132 & 1.550 & 102.0 \\
\hline
\end{tabular}

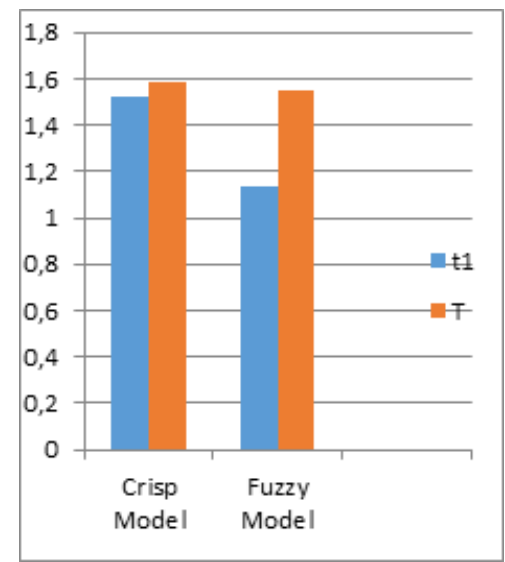

Figure 3: Comparison of Time parameter

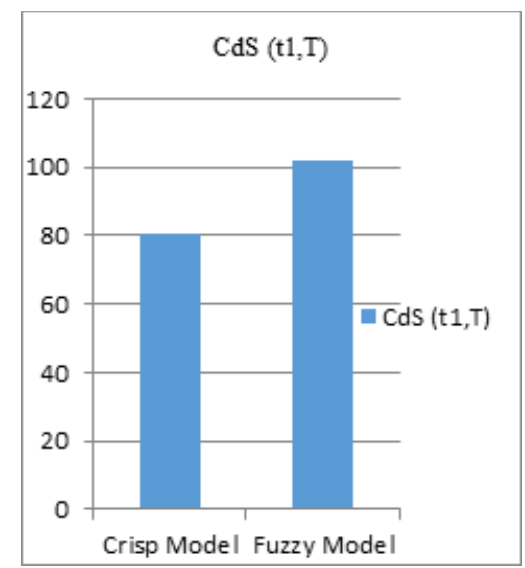

Figure 4: Comparison of Cost parameter

\section{SPECIAL CASES}

In this section, we consider the following two special cases:

(i) For $\delta=0$, the proposed model changes from partially backlogged to fully backlogged. In fully backlogged inventory model, the total cost function is given by 
DOI: 10.14807/ijmp.v12i2.1212

$$
C\left(t_{1}, T\right)=\frac{1}{T}\left\{t_{1}^{3}\left(\frac{a h}{6 \theta}+\frac{c_{2} a \theta}{2}\right)+\frac{b}{2} c_{3}\left(T-t_{1}\right)^{2}+k_{1} t_{1}+k_{2}\right\}
$$

(ii) For $\mathrm{k}_{1}=0$, the proposed model changes from linearly increasing type ordering cost to constant type ordering cost model. Subsequently, in constant ordering cost inventory model, the total cost function is given by

$$
C\left(t_{1}, T\right)=\frac{1}{T}\left\{t_{1}^{3}\left(\frac{a h}{6 \theta}+\frac{c_{2} a \theta}{2}\right)+\frac{b}{2}\left(c_{3}+\delta c_{4}\right)\left(T-t_{1}\right)^{2}+k_{2}\right\}
$$

\section{MANAGERIAL IMPLICATIONS AND LIMITATIONS}

\subsection{Managerial Implications}

The following managerial implications are explored from the proposed research work: which is supportive of any operational managers in the manufacturing unit:

- The model developed in this research work is supportive for the inventory management, where the holding cost and ordering cost are is continuously increasing with time, and where the decision maker targets to optimize the average total inventory costs.

- The model considered the demand rate, ordering cost, and holding cost of the items with some ambiguity which is a natural case, and therefore, provides an approach to the inventory managers to optimize the various inventory costs with ambiguity.

\subsection{Limitations}

There exist some limitations of the proposed model which are listed below:

- In the derivation of the proposed model, we used the approximations of exponential term. Therefore, this model will provide the approximate results only.

- The examples, which we used to validate the proposed model, are hypothetical.

- The proposed problem is limited to vagueness only. However, in real-world applications, the DM has to encounter the randomness and multiple choice cases.

- The role of deterioration is assumed constant. However, in real-world applications, the DM has to face the time dependent deterioration.

\section{CONCLUSIONS AND FUTURE DIRECTIONS}

In this paper, a deteriorating inventory model with time-dependant demand rate and varying holding cost is presented. The shortages are permitted and partially backlogging case is assumed. The classical optimization technique is implemented over the cost function to 
DOI: 10.14807/ijmp.v12i2.1212

obtain the optimal order quantity and optimal total cost. For the practical application of this model, a solved example is considered by using the MATHEMATICA -8.0 package. The proposed model can assist the manufacturer and retailer in accurately determining the economic order quantity, cycle time and total cost, to be used in inventory control of seasonal items.

There are several directions for future research. We can discuss the sensitivity test to identify the most sensitive parameters in the model. Another direction of research is to consider the randomness in inventory parameter. Also, the demand and holding cost may be considered as quadratic time dependent.

\section{REFERENCES}

Abad, P. (1996). Optimal pricing and lot-sizing under conditions of perishability and partial backordering. Management Science, 42, 1093-1104.

Abad, P. (2001). Optimal price and order-size for a reseller under partial backlogging. Computers and Operation Research, 28, 53-65.

Alamri, A., \& Balkhi, Z. (2007). The effects of learning and forgetting on the optimal production lot size for deteriorating items with time varying demand and deterioration rates. International Journal of Production Economics, 107, 125-138.

Biswas, A. K., \& Islam, S. (2019). A fuzzy EPQ model for non-instantaneous deteriorating items where production depends on demand which is proportional to population, selling price as well as advertisement. Independent Journal of Management \& Production, 10( 5), 1679-1703.

Chang, H., \& Dye, C. (1999). An EOQ model for deteriorating items with time varying demand and partial backlogging. Journal of the Operational Research Society, 50, 11761182.

Chung, K. J., \& Ting, P. S. (1993). A heuristic for replenishment of deteriorating items with a linear trend in demand. Journal of the Operational Research Society, 44, 1235-1241.

Dave, U., \&Patel, L. (1981). (T, si)-policy inventory model for deteriorating items with time proportional demand. Journal of the Operational Research Society, 32, 137-142.

Dutta, D., \& Kumar, p. (2015a). A partial backlogging inventory model for deteriorating items with time-varying demand and holding cost: An interval number approach. Croatian Operational Research Review, 6(2), 321-334. DOI:10.17535/crorr.2015.0025

Dutta, D., \& Kumar, P. (2015b). Application of fuzzy goal programming approach to multiobjective linear fractional inventory model, International Journal of Systems Science, 46(12), 2269-2278.

Dye, C. (2007a). Determining optimal selling price and lot size with a varying rate of deterioration and exponential partial backlogging. European Journal of Operational Research, 181, 668-678.

Dye, C. (2007b). Joint pricing and ordering for a deteriorating inventory with partial backlogging. Omega, 35(2), 184-189. 
Goyal, S., \& Giri, B. (2001). Recent trends in modeling of deteriorating inventory. European Journal of Operational Research, 134, 1-16.

He, Y., Wang, S., \& Lai, K. (2010). An optimal production-inventory model for deteriorating items with multiple-market demand. European Journal of Operational Research, 203(3), 593-600.

Ho, L-.H., Cheng, C-.L., Yang, M-.F., \& Lo, M-.C. (2007). (Q, r) inventory model with backorder discount in fuzzy demand and fuzzy ordering cost. Journal of Information and Optimization Sciences, 28(4), 561-572.

Hung, K. (2011). An inventory model with generalized type demand, deterioration and backorder rates. European Journal of Operational Research, 208(3), 239-242.

Jalan, A., Giri, R., \& Chaudhary, K. (1996). EOQ model for items with weibull distribution deterioration shortages and trended demand. International Journal of System Science, 27, 851-855.

Khalifa, H. A. E., Kumar, P., \& Smarandache, F. (2020). On optimizing neutrosophic complex programming using lexicographic order. Neutrosophic Sets and Systems, 32, 330343.

Kumar, P. (2019). An inventory planning problem for time-varying linear demand and parabolic holding cost with salvage value. Croatian Operational Research Review, 10(2), 187-199. DOI:10.17535/crorr.2019.0017

Kumar, P., \& Keerthika, P. S. (2018). An inventory model with variable holding cost and partial backlogging under interval uncertainty: Global criteria method. International Journal of Mechanical Engineering \& Technology, 9(11), 1567-1578.

Liao, J. (2008). An EOQ model with non instantaneous receipt and exponential deteriorating item under two-level trade credit. International Journal of Production Economics, 113, 852-861.

Mandal, B. (2010). An EOQ inventory model for Weibull distributed deteriorating items under ramp type demand and shortages. OPSEARCH, 47(2), 158-165.

Yang, M-.F., Tu, H-.J., \& Wang, C-.M. (2007). Determining the single-vender and singlebuyer inventory strategy with fuzzy setup cost and fuzzy ordering cost. Journal of Statistics and Management Systems, 10(4), 499-510.

Mishra, V. K., Singh, L. S. (2011). Deteriorating inventory model for time dependent demand and holding cost with partial backlogging. International Journal of Management Science and Engineering Management, 6(4), 267-271.

Rodrigues, P. C. C., Marins, F. A. S., \& Souza, F. B. D. (2017). Application of a mathematical model for the minimization of costs in a micro-company of the graphic sector. Independent Journal of Management \& Production, 8(5), 676-692.

Roy, A. (2008). An inventory model for deteriorating items with price dependent demand and time varying holding cost. Advanced Modeling and Optimization, 10, $25-37$.

Shah, N., \& Shukla, K. (2009). Deteriorating inventory model for waiting time partial backlogging. Applied Mathematical Sciences, 3, 421-428.

Skouri, K., Konstantaras, S., \& Ganas, I. (2009). Inventory models with ramp type demand rate, partial backlogging and weibull deterioration rate. European Journal of Operational Research, 192, 79-92. 
Teng, J., Ouyang, L., \& Chen. L. (2007). A comparison between two pricing and lot-sizing models with partial backlogging and deteriorated items. International Journal of

Production Economics, 105, 190-203.

Tripathi, R. P. (2011). Inventory model with time dependent demand rate under inflation when supplier credit linked to order quantity. International Journal of Business and Information Technology, 1(3), 174-183.

Wang, J., \& Shu, Y. F. (2005). Fuzzy decision modelling for supply chain management. Fuzzy Sets and System, (150), 107-127.

Wu, O., \& Cheng (2005). An inventory model for deteriorating items with exponential declining demand and partial backlogging. Yugoslav Journal of Operations Research, 15(2), 277-288.

Zadeh, L. A. (1965). Fuzzy sets, Information and Control, (8), 338-353.

Zimmermann, H. J. (1985). Application of fuzzy set theory to mathematical programming, Information Science, (36), 29-58.

\section{Appendix-A}

The maximum amount of demand backlogged per cycle is as follows:

$$
D_{B}=-I_{2}(T)=\frac{b}{\delta}\left[\log \left\{1+\delta\left(T-t_{1}\right)\right\}\right]
$$

So, the order quantity per cycle is given by

$$
Q=I_{\max }+D_{B}=\frac{a}{\theta}\left[\frac{1}{\theta}+\left(t_{1}-\frac{1}{\theta}\right) e^{\theta t_{1}}\right]+\frac{b}{\delta}\left[\log \left\{1+\delta\left(\mathrm{T}-t_{1}\right)\right\}\right]
$$

$=\frac{a}{\theta}\left[\frac{1}{\theta}+\left(t_{1}-\frac{1}{\theta}\right)\left(1+\theta t_{1}+\frac{\theta^{2} t_{1}^{2}}{2}\right)\right]+\frac{b}{\delta}\left[\delta\left(\mathrm{T}-t_{1}\right)-\frac{\delta^{2}\left(\mathrm{~T}-t_{1}\right)^{2}}{2}\right]$, using Maclaurin series,

$=\frac{a}{\theta}\left[\frac{1}{\theta}+\left(t_{1}+\theta t_{1}^{2}-\frac{1}{\theta}-t_{1}-\frac{\theta t_{1}^{2}}{2}\right)\right]+\mathrm{b}\left[\mathrm{T}-t_{1}-\frac{\delta\left(\mathrm{T}-t_{1}\right)^{2}}{2}\right]$, taking terms upto power two, as $\theta<1$.

$Q=a\left(\frac{t_{1}^{2}}{2}\right)+\mathrm{b}\left[\mathrm{T}-t_{1}-\frac{\delta\left(\mathrm{T}-t_{1}\right)^{2}}{2}\right]$

The inventory holding cost per cycle is

$$
C_{H}=\int_{0}^{t_{1}} c_{1}(t) I_{1}(t) \mathrm{dt}
$$

$=\int_{0}^{t_{1}}-\frac{a h t}{\theta}\left[\left(\mathrm{t}-\frac{1}{\theta}\right)-\left(t_{1}-\frac{1}{\theta}\right) e^{\theta\left(t_{1}-t\right)}\right] \mathrm{dt}$

$=-\frac{a h}{\theta} \int_{0}^{t_{1}}\left[\mathrm{t}^{2}-\frac{t}{\theta}-\left(t_{1}-\frac{1}{\theta}\right) \mathrm{e}^{\theta \mathrm{t}_{1}} t e^{-\theta \mathrm{t}}\right] \mathrm{dt}$

$=-\frac{a h}{\theta}\left[\frac{t_{1}^{3}}{3}-\frac{t_{1}^{2}}{2 \theta}+\left(t_{1}-\frac{1}{\theta}\right)\left(\frac{t_{1}}{\theta}+\frac{1}{\theta^{2}}-\frac{e^{\theta t_{1}}}{\theta^{2}}\right)\right]$

Expanding $e^{\theta t_{1}}$ into ascending powers of $\theta t_{1}$, taking the terms up to $2^{\text {nd }}$ power in $\theta$, and neglecting all terms, as $\theta<1$. After simplification we have

$$
C_{H}=\frac{a h}{6 \theta} t_{1}^{3}
$$

The deterioration cost per cycle is

$$
C_{D}=c_{2}\left[I_{\max }-\int_{0}^{t_{1}} R(t) d t\right]
$$

$=c_{2}\left[\frac{a}{\theta}\left\{\frac{1}{\theta}+\left(t_{1}-\frac{1}{\theta}\right) e^{\theta t_{1}}\right\}-\int_{0}^{t_{1}} a t d t\right]$

$=c_{2}\left[\frac{a}{\theta}\left\{\frac{1}{\theta}+\left(t_{1}-\frac{1}{\theta}\right) e^{\theta t_{1}}\right\}-\frac{a t_{1}^{2}}{2}\right]$

$=c_{2} a\left[\frac{1}{\theta^{2}}+\frac{e^{\theta t_{1}}}{\theta}\left(t_{1}-\frac{1}{\theta}\right)-\frac{t_{1}^{2}}{2}\right]$ 
DOI: 10.14807/ijmp.v12i2.1212

$=c_{2} a\left[\frac{1}{\theta^{2}}-\frac{t_{1}^{2}}{2}+\left(\frac{t_{1}}{\theta}-\frac{1}{\theta^{2}}\right)\left(1+\theta t_{1}+\frac{\theta^{2} t_{1}^{2}}{2}\right)\right]$

$=c_{2} a\left[\frac{1}{\theta^{2}}-\frac{t_{1}^{2}}{2}+\frac{t_{1}}{\theta}-\frac{1}{\theta^{2}}+t_{1}^{2}-\frac{t_{1}}{\theta}+\frac{\theta t_{1}^{3}}{2}-\frac{t_{1}^{2}}{2}\right]$

$=\frac{c_{2} a}{2}\left(\theta t_{1}^{3}\right)$

The total ordering cost per order for the cycle [0, T] is given by

$C_{o}(t)=k_{1} t_{1}+k_{2}$ for $0 \leq t_{1} \leq T$

The shortage cost per cycle is

$C_{S}=c_{3}\left[-\int_{t_{1}}^{T} I_{2}(t) d t\right]$

$=-c_{3} \frac{b}{\delta} \int_{t_{1}}^{T}\left[\log \{1+\delta(\mathrm{T}-\mathrm{t})\}-\log \left\{1+\delta\left(\mathrm{T}-t_{1}\right)\right\}\right] \mathrm{dt}$

$=c_{3} \mathrm{~b}\left[\frac{T-t_{1}}{\delta}-\frac{1}{\delta^{2}} \log \left\{1+\delta\left(\mathrm{T}-t_{1}\right)\right\}\right]$

The lost sale cost per cycle is

$C_{L}=c_{4} \int_{t_{1}}^{T}\left[1-\frac{1}{1+\delta(\mathrm{T}-\mathrm{t})}\right] \mathrm{b} \mathrm{dt}=c_{4} \mathrm{~b}\left[\left(\mathrm{~T}-t_{1}\right)-\frac{1}{\delta} \log \left\{1+\delta\left(\mathrm{T}-t_{1}\right)\right]\right.$ 